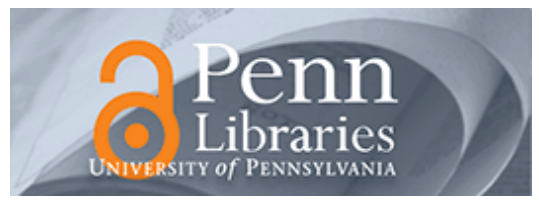

University of Pennsylvania

ScholarlyCommons

Finance Papers

Wharton Faculty Research

2008

\title{
Common Liquidity Shocks and Market Collapse: Lessons From the Market for Perps
}

Chitru S. Fernando

Richard J. Herring

University of Pennsylvania

Avanidhar Subrahmanyam

Follow this and additional works at: https://repository.upenn.edu/fnce_papers

Part of the Finance and Financial Management Commons

\section{Recommended Citation}

Fernando, C. S., Herring, R. J., \& Subrahmanyam, A. (2008). Common Liquidity Shocks and Market Collapse: Lessons From the Market for Perps. Journal of Banking and Finance, 32 (8), 1625-1635. http://dx.doi.org/10.1016/j.jbankfin.2007.11.011

This paper is posted at ScholarlyCommons. https://repository.upenn.edu/fnce_papers/397

For more information, please contact repository@pobox.upenn.edu. 


\title{
Common Liquidity Shocks and Market Collapse: Lessons From the Market for Perps
}

\author{
Abstract \\ We show how a high degree of commonality in investor liquidity shocks can diminish incentives for \\ intermediaries to keep markets open and lead to market collapse, even without information asymmetry or \\ news affecting fundamentals. We motivate our model using the perpetual floating-rate note market where \\ two years of explosive growth - in which issues by high quality borrowers were placed with institutional \\ investors and traded in a liquid secondary market - were followed by a precipitous collapse when market \\ intermediaries withdrew due to large order imbalances. We shed new light on the trade-off between \\ ownership concentration and market liquidity.

\section{Disciplines} \\ Finance and Financial Management
}




\title{
Common liquidity shocks and market collapse: Lessons from the market for Perps *
}

\author{
Chitru S. Fernando \\ Michael F. Price College of Business, University of Oklahoma \\ Richard J. Herring \\ The Wharton School, University of Pennsylvania
}

Avanidhar Subrahmanyam

The Anderson School, UCLA

\begin{abstract}
We show how a high degree of commonality in investor liquidity shocks can diminish incentives for intermediaries to keep markets open and lead to market collapse, even without information asymmetry or news affecting fundamentals. We motivate our model using the perpetual floating rate note market where two years of explosive growth -- in which issues by high quality borrowers were placed with institutional investors and traded in a liquid secondary market -- were followed by a precipitous collapse when market intermediaries withdrew due to large order imbalances. We shed new light on the trade-off between ownership concentration and market liquidity.
\end{abstract}

November 2007

Keywords: ownership concentration, intermediation, market liquidity, common liquidity shocks, market collapse JEL classification: G12, G15, G18

\footnotetext{
* This paper was reviewed and accepted while Prof. Giorgio Szego was the Managing Editor of The Journal of Banking and Finance and by the past Editorial Board. Please address all correspondence to A. Subrahmanyam, Anderson School, UCLA, Los Angeles, CA 90095-1481; phone: (310) 825-5355; email: subra@anderson.ucla.edu. We thank Franklin Allen, Sugato Bhattacharyya, Tarun Chordia, Gunter Dufey, Michael Fleming, Campbell Harvey, Steve Jones, Richard Kihlstrom, Paul Kleindorfer, Arvind Krishnamurthy, Ananth Madhavan, Bill Megginson, Tom Noe, Todd Pulvino, Raghuram Rajan, Russ Robins, Patrik Sandas, Nejat Seyhun, Chester Spatt, Giorgio Szego (the editor) Kathy Yuan, an anonymous referee and seminar participants at the AFA and WFA meetings, the Northwestern Conference on Imperfect Capital Markets, the Georgia Tech Conference on International Finance, Wharton, Michigan, Alabama, American University, Calgary, Claremont Graduate University, Indiana, Iowa, Oklahoma, Texas A\&M, Tulane, Federal Reserve Board, and Federal Reserve Bank of New York for valuable discussions and comments on previous versions of this paper. We also thank market participants in London, Tokyo and New York who shared their insights with us. We are grateful to the Weiss Center for International Financial Research for supporting the collection of data, and a grant from the Sloan Foundation to the Wharton Financial Institutions Center for supporting the completion of this research. Si Chen, Hector Campos, Nauman Malik, David Muir and Steve Mykijewycz provided excellent research assistance.
} 
Liquidity, according to Keynes, offers a classic example of the fallacy of composition: what is true for a part is not necessarily true for the whole. The ability to reverse positions and get out quickly vanishes when everyone tries to do it at once. - Merton Miller (1991).

\section{Introduction}

There has been considerable attention paid in the recent literature to the question of how ownership structure, and in particular ownership by large investors, affects market liquidity, corporate governance and the value of the firm. One strand of this literature has focused on the tradeoff between the value of monitoring by a concentration of large investors and the cost of illiquidity of a firm's shares. Bhide (1993) argues that policies aimed at increasing the liquidity of a firm's shares by promoting diffused ownership reduce the incentives for large investors to monitor. This is because of free-riding by small investors, and because higher liquidity reduces the cost to large investors of "voting with their feet." In contrast, Maug (1998) argues that a liquid market makes it easier and cheaper for investors to acquire and hold large concentrations of a security, and makes corporate governance more effective. ${ }^{1}$ A basic premise underlying Maug's argument is that concentrated ownership of securities can be reconciled with liquid secondary markets, notwithstanding the inherent reduction in liquidity that results from blockholdings and a smaller investor base.

We revisit this premise and provide a new perspective on the ownership-liquidity debate by studying an aspect of concentrated ownership that has not received much attention in the literature: the risk of a market collapse due to common liquidity shocks, i.e., liquidity shocks that are highly correlated across investors, causing a common drop in demand for a security. We argue that this risk increases with ownership concentration, especially among homogeneous investors. Our context is the market for perpetual floating rate notes (perps). Perps are floating rate notes (FRNs) of infinite

\footnotetext{
${ }^{1}$ See also, for example, Bolton and von Thadden (1998), Kahn and Winton (1998) and Pritsker (2004).
} 
maturity, bearing a coupon indexed to a benchmark rate (usually the London Inter-Bank Offered Rate, LIBOR) and re-set at fixed intervals (usually every three or six months). The first perp was issued in 1984. Issuers of perps were largely European, Australian and North American banks and institutions with generally very high credit ratings. Perps were traded in well-organized markets by sophisticated investors, primarily banks and other institutions. The market for perps grew rapidly and the volume of perps outstanding reached $\$ 22$ billion by the end of 1986 . Perps traded at close to par value in the secondary market, which was highly liquid until it began to collapse precipitously in December 1986. Secondary market prices experienced drops ranging from $12-25 \%$, and trading volume dried up for all perp issues. While the majority of the perps issued during the 1984-1986 period remain outstanding, the secondary market has not regained its liquidity.

We document evidence later in the paper that attributes the loss of liquidity in the perp market directly to the concentrated institutional ownership of perps. Until December 1986, the secondary market remained very liquid despite its narrow investor base. However, once a common drop in demand across perp investors due to highly correlated liquidity shocks caused significant losses to market intermediaries and prompted them to withdraw from the market, the secondary market was unable to recover its liquidity.

Our study provides new insights into the phenomenon of market collapse by explicitly modeling how correlated liquidity shocks experienced by investors can cause intermediaries to withdraw liquidity. Central to our model is a basic Walrasian batch market in which risk-averse investors are symmetrically informed and trade only in response to liquidity shocks. These shocks have both an idiosyncratic component and a component that is common across all investors, i.e., a 
systematic component. ${ }^{2}$ Trading is facilitated by risk-neutral market intermediaries (e.g., dealers or exchanges) that contract a bid-ask price spread with investors to recover their costs of offering the market. Liquidity shocks that have a large common component, i.e., are highly correlated across investors, prevent investors from trading with each other and the resulting drop in trading volume causes losses to market makers. Thus, the decision by market making entities to offer the market depends on their assessment of common liquidity risk. Market makers can withdraw and cause markets to collapse when the degree of commonality in liquidity shocks exceeds a threshold level. Our implications differ from models in which markets break down due to a worsening of information asymmetry about asset price fundamentals across market participants. In these models (e.g., Glosten and Milgrom, 1985; Bhattacharya and Spiegel, 1991), uninformed investors withdraw from the market for fear of being taken advantage of by better-informed market participants, causing a market failure. We achieve a comparable result in our model without asymmetric information. This difference has important ramifications for how a crisis can be resolved. If the collapse is caused by an exacerbation of asymmetric information, it can be resolved by alleviating the information asymmetry. If the collapse is caused by a common liquidity shock, however, prices will rebound only if market participants believe that the risk of a recurrence of such shocks is small. Unlike in models of rational price bubbles and their collapse (e.g., Kindleberger, 1978; Allen and Gale, 2000) our model abstracts from agency problems or imperfect information about asset values.

Our model is related to the work of Brunnermeier and Pedersen (2007), who examine the links between a security's market liquidity and traders' funding liquidity. In their model, the ability for traders to provide market liquidity depends on their funding liquidity and the supply of liquidity

\footnotetext{
2 Several recent studies have documented common factors in market liquidity, including Chordia, Roll and Subrahmanyam (2000), Hasbrouck and Seppi (2001), and Pástor and Stambaugh (2003). However, the potential for common factors in liquidity shocks experienced by investors to cause market collapse has not been rigorously explored in the literature.
} 
is reduced when the funding constraints tighten. Kyle and Xiong (2001) and Gromb and Vayanos (2002) also develop models where wealth constraints experienced by market participants give rise to withdrawal of market liquidity. In contrast, the key driver of market liquidity in our model is the demand for liquidity arising from the liquidity shocks experienced by investors. As the correlation across individual liquidity shocks increases, the volume of trading declines, thereby negatively impacting the viability of the market from the standpoint of the market makers who have invested capital to make the market available. They respond by either increasing their spreads to recover more revenue (thereby further exacerbating the market illiquidity) or by reducing spreads to stimulate trading. If neither of these liquidity supply responses bring in the revenue needed to recover their investment, market makers will stop offering the market.

We find that these alternative explanations do not adequately account for this collapse. While our model predicts that the market for perps could recover after a number of periods without an additional high commonality state, a unique and puzzling aspect of the perp market is that such a recovery did not occur. We attribute this lack of recovery, at least initially, to the unwillingness of Japanese banks (which purchased the vast majority of perps) to realize capital losses by selling even a part of their holdings at substantially lower prices to help restore market liquidity.

The rest of the paper is organized as follows. In Section 2, we discuss the rise and fall of the market for perps. In Section 3, we develop our basic theoretical model, which relates market failure to commonality in liquidity shocks. In Section 4, we discuss potential alternate explanations for the collapse of the perp market, and provide a brief postscript on attempts to restore liquidity to the market. Section 5 concludes.

\section{The rise and fall of the perp market ${ }^{3}$}

\footnotetext{
${ }^{3}$ The discussion in this section draws heavily on numerous interviews by the authors with market participants.
} 
The perp market was launched in April 1984 with an inaugural issue by NatWest (Citibank issued a "quasi-perp" in 1980), and perps were quickly hailed as a successful financial innovation. In this section, we examine the rise and fall of the perp market, and link its initial success to the growth of investor confidence about the liquidity of the secondary market for perps, and its collapse to a common liquidity shock that substantially increased expectations of the reoccurrence of a common liquidity shock and led market makers to abandon the market permanently.

\subsection{The rise}

Floating Rate Notes (FRNs), both dated and perpetual, have particular investor appeal due to stability of principal value when interest rates are expected to be volatile. Issuance of perps was especially attractive to banks that were experiencing pressures to increase their regulatory capital during the mid-eighties and saw perps as being well suited for this purpose because interest payments on perps, unlike dividends on preferred stock, were tax-deductible (IFR, 1987). Indeed, all issues of perps include a provision that allows the borrower to automatically call the perp if the tax authorities disallow the deductibility as a business expense. U.S. issuers did not venture into the market until just before it collapsed, having initially held back due to a presumption that the Internal Revenue Service (IRS) would construe the interest paid on perps as the equivalent of dividends and therefore not tax-deductible.

Banks sought permission to count issuance of perps as capital for regulatory purposes. The Bank of England, Britain's central bank, did not permit the first issue of perps by NatWest to qualify as regulatory capital. But, in rejecting this request, the Bank of England set conditions under which a perp could be counted as regulatory capital. The critical requirement stipulated by the Bank of England was that perps must be automatically converted into preferred stock in the event of default. Following the Bank of England, several other central banks - including those in Australia, Canada, France and the United States — established conditions under which perps could be counted as capital 
for regulatory purposes, making the issuance of perps a feasible solution to the need to increase regulatory capital. The Japanese authorities were about to authorize the use of perps to meet capital requirements when the market began to collapse in December 1986.

The challenge in marketing perps was to convince prospective investors that perps were close substitutes for fixed-maturity, floating-rate notes and money market instruments. Underwriters argued that the floating-rate feature made the interest-rate risk on perps equivalent to that on any other floating rate instrument. Moreover, they addressed concerns about the infinite maturity of perps by arguing that they could be sold any time at a price close to par in a broad, deep secondary market. Investor confidence in the liquidity of the secondary market was thus key to pricing perps in line with money market and other finite-maturity, floating-rate instruments of comparable quality. The initial rapid growth of issues and the decline of spreads suggest that underwriters were increasingly successful in this regard.

Banks, especially Japanese banks, were eager to invest in floating-rate, dollar-denominated instruments during the eighties and became the main buyers of perps. Market observers estimate that as much as $80 \%$ of the perps outstanding were placed with Japanese financial institutions. Overall, banks held an estimated $90 \%$ of outstanding perps (IFR, December 6, 1986, p. 3633). They found perps an attractive way to increase returns over interbank placements (which yielded LIBOR or less) at what appeared to be little additional risk.

From 1984 to the end of 1986 the spread over LIBOR that perps were priced at steadily declined to around 10-15 basis points, indicating that prices increased as investors gained confidence in the liquidity of the secondary market. The spread relative to the LIBOR benchmark seemed sufficiently attractive to induce some governments, such as those of Belgium, Denmark and Sweden, to issue perps, although they had no tax or regulatory incentive to do so. The volume of perps outstanding stood at $\$ 3.5$ billion by the end of $1984, \$ 16$ billion by the end of 1985 , and $\$ 22$ billion 
by the end of 1986, accounting for $29 \%$ and $46 \%$, respectively, of total FRN issuance in the latter two years (Meerschwam, 1987). Through 1986, nearly 60 perps were issued.

The perp market was a dealer market, which maximized the potential for liquidity relative to other market structures. The market's liquidity increased steadily as evidenced by transactions costs and the size of the standard lot for which dealers would quote a price. By November 1986, more than fifty dealers stood ready to quote two-way prices for standard lots of $\$ 5$ million at a 10 basis point spread (Williams and Hole, 1987). Although volume data for individual issues is not available, an indirect indication of volume can be inferred from the number of perp issues in the Euroclear listing of the twenty most actively traded money market issues each month. Perps were among the most actively traded money market instruments through the first quarter in 1987, with average aggregate daily volumes of as much as $\$ 1$ billion recorded by Euroclear during this period.

\subsection{The collapse}

The success of the perp market was short-lived. The proximate cause of the market collapse appears to have been a rumor of an international agreement on bank capital requirements that would require banks to deduct holdings of perps (and other capital securities) issued by other banks in computing their capital for regulatory purposes. The Basel Committee on Banking Regulation and Supervisory Practices (Basel Committee) was expected to take the view that the banking system would be more resilient, and the danger of contagion would be less, if nonbanks held capital claims

on banks. The basis for this rumor was the proposed Anglo-American Accord on the assessment of capital adequacy. The proposed regulations were officially released in the United States on January 8,1987 , but major banks were well aware of the general outlines of the approach. The part of the proposal that was of particular relevance to the market for perps was the decision regarding bank holdings of other banks' capital instruments. The official release (Comptroller of the Currency, Federal Deposit Insurance Corporation and Federal Reserve Board, 1987, p.7) noted that the Bank of 
England already deducts such holdings from capital: “...except for limited concessions to allow some banks to play an active role in market-making in the primary (new issues) and/or secondary markets. This policy will be maintained. The U.S. authorities accept the principle underlying this policy and will monitor bank holdings of capital instruments issued by other banks and may, as appropriate, deduct these items on a case-by-case basis."

Although the proposed regulations pertained only to British and American banks, the potential implications for banks in Japan were clear (Wagster, 1996). As one market participant observed, "The Ministry of Finance in Tokyo must eventually insist on similar provisioning, particularly if Japanese banks are allowed to offer perpetual debt themselves. That will just about kill off the market," (IFR, December 6, 1986, p. 3633). Since the majority of perps were issued by banks, even the possibility of this kind of change in regulations provided a powerful incentive for banks holding perps to sell.

On Wednesday, December 3, 1986, sell orders overwhelmed almost all of the core fifty dealers in the perp market and they suspended normal trading (Financial Times, Dec. 4, 1986, p.38). The feared regulatory change caused banks (that held most of the outstanding perps) to attempt to sell at the same time, producing a one-way market. In our model, we characterize this as a common liquidity shock that affected most holders of perps in the same way at the same time. Although secondary market trading enables individuals to mitigate idiosyncratic liquidity shocks, the market mechanism breaks down when the shocks are expected to apply simultaneously in the same direction for all investors, and that is precisely what happened to the secondary market for perps.

As participants noted in the financial press at the time of the market collapse, "We have seen the door slammed shut on the only way in which investors can really leave this market-trading liquidity.... The whole psychology of this market has now changed—it's never going to be the same again," (IFR, December 6, 1986, p. 3632). Along the same lines, another market participant (IFR, 
January 10, 1987, p. 3) concluded, "The crisis is basically one of confidence, and perpetuals are undergoing a general re-evaluation of worth separate from any underlying change in the quality and credit of the debt involved and external influences such as interest rates."

Ironically, the rumor proved to be false, although market participants could not confirm this until the Basel Committee issued a Consultative Paper a year later, officially rejecting this unfavorable treatment of perps and other bank capital issues. The Committee's Consultative Paper of December 1987 (p.9) stated: "The Committee carefully considered the possibility of requiring deduction of banks' holdings of capital issued by other banks.... Several G-10 supervisory authorities currently require such a deduction to be made in order to discourage the banking system as a whole from creating cross-holdings of capital, rather than drawing capital from outside investors. The Committee is very conscious that such double-gearing (or "double-leveraging") can have systemic dangers for the banking system by making it more vulnerable to the rapid transmission of problems from one institution to another... Despite these concerns, however, the Committee as a whole is not presently in favor of a general policy of deducting all holdings of other banks' capital, on the grounds that to do so could impede certain significant and desirable changes taking place in the structure of domestic banking systems."

By then, however, the damage to investor confidence in market liquidity was irreparable. From Wednesday, December 3, 1986, the secondary market began to collapse. Market makers withdrew from the market in anticipation of continuing losses. Typical dealer-to-dealer price spreads increased from 10 basis points to 50 basis points while at the same time standard lot sizes declined from $\$ 5$ million to $\$ 1$ million (Williams and Hole, 1987). The number of active market makers plummeted from 50 to fewer than 10 by March 1987, and these functioned mainly as brokerstrying to match buyers with sellers - rather than standing ready to buy or sell at a stated spread. After December 1986, only perps issued by the British clearing banks made the list of the twenty 
most active issues maintained by Euroclear. By May 1987, perps had dropped from the list altogether. In the absence of a liquid secondary market, the new issue market completely disappeared.

Secondary market prices fell sharply during this period. Figure 1 plots the value from November 1984 through August 1988 of a price index of eleven perps issued by British clearing banks. The sudden collapse and lack of recovery of the secondary market is clearly evident.

[Insert Figure 1 about here]

The events of December 1986 had exposed the narrow investor base of the secondary market for perps. The episode made clear that the liquidity of the perp secondary market depended critically on confidence in the breadth of the market -- on the belief that other investors would not change their portfolio preferences in the same way at the same time. When a liquidity shock affected all the bank holders of perps, the negative implications of the overwhelming concentration of perps in the hands of Japanese banks for the prospect of additional systemic liquidity shocks became all too evident. The absence of any evidence of contagion, i.e., the perp collapse spreading to other securities markets or being caused by events in other markets, lends support to our view that the perp collapse was rooted in the narrow perp investor base.

In the next section, we formalize the above arguments and develop our simple theoretical model to explain how common liquidity risk can give rise to market collapse despite symmetrically informed market participants and lack of uncertainty about future cash flows. While the model is motivated and illustrated by the perp collapse, we argue that it is applicable in any market setting characterized by a significant level of common liquidity risk.

\section{The Model}

In this section, we present our model and relate liquidity to asset prices by considering a model where investors receive imperfectly correlated liquidity shocks and then rebalance their 
holdings by trading in an asset market. We assume that trading occurs in a Walrasian batch market in which all trades clear at the same price subject to a bid-ask spread. Trading is facilitated by $M$ identical, competing, risk-neutral market intermediaries (exchanges or dealers), each of whom incurs a fixed cost of $c$ in setting up the market for each round of trade. ${ }^{4}$ This cost may be viewed as the opportunity cost of providing immediacy and is recovered by way of the spread. We first consider the basic case with one round of trading and then examine a more general setting with multiple rounds of trading to determine how liquid markets can become illiquid.

\subsection{The basic case}

There is a risky asset which is traded at period 1 and pays off $\theta+\varepsilon$ in period 2, where $\theta$ is non-random at date 1 and $\varepsilon$ is normally distributed with mean zero and variance $v_{\varepsilon}$. Thus, investors and intermediaries have knowledge of the $\theta$ component but not of the $\varepsilon$ component. We assume that there are $N$ outside investors, each with an endowment $w_{i}$. All endowments are normally distributed with mean zero and variance $v_{w}$, and a common correlation $\rho$. Therefore these stochastic endowments may be viewed as liquidity shocks which force investors to attempt to rebalance their holdings of the risky asset in the secondary market. ${ }^{5}$ The random variables $w_{i}$ are independent of $\theta$ and $\varepsilon$. All investors have exponential utility with a risk aversion coefficient $R$. In addition, a linear technology is used to set the spread, so that the spread on an order of size $x$ is $\lambda x$, with each side paying $0.5 \lambda x .^{6}$

\footnotetext{
${ }^{4}$ Multiple market intermediaries are not necessary for our basic result; it holds even where a single intermediary makes an entry decision.

${ }^{5}$ See, for example, Glosten (1989), Bhattacharya and Spiegel (1991) and Spiegel and Subrahmanyam (1992) for a similar formulation of liquidity shocks. Common shocks to endowments can be caused by a variety of systemic events such as tax and regulatory changes.

${ }^{6}$ We have adopted this particular formulation of transactions costs purely for tractability, without loss of generality of our key results. See, for example, Brennan and Subrahmanyam (1996) and Fernando (2003).
} 
A key parameter of focus in our analysis is the endowment correlation, $\rho$, which proxies in our model for the degree to which investors are exposed to common liquidity shocks. As noted in Section 1, we suggest that the market's exposure to common liquidity risk is higher when the security is marketed to a small group of institutional investors rather than a large group of diffuse individual investors. From an empirical standpoint, this can happen because institutional investors engage in characteristic herding (Sias, 2004). Also, some institutions, such as banks and insurance companies, may be more susceptible to common macroeconomic factors including changes in taxes and regulations. Finally, institutional investors act as financial intermediaries by pooling individuals' liquidity needs (Edelen, 1999), which leads to greater commonality in liquidity shocks.

Denote each investor's desired trade as $x_{i}$. Using the mean-variance analysis implied by exponential utility, each investor maximizes $E\left(K_{i}\right)-0.5 R \operatorname{var}\left(K_{i}\right)$, where $K_{i}=(\theta+\varepsilon)\left(x_{i}+w_{i}\right)-x_{i}\left(P+0.5 \lambda x_{i}\right)$ denotes the investor's end-of-period wealth and $P$ is the market-clearing price at period 1. The objective function reduces to $x_{i}(\theta-P)+w_{i} \theta-0.5 \lambda x_{i}^{2}-0.5 R v_{\varepsilon}\left(x_{i}+w_{i}\right)^{2}$, so that the demand of each outside investor at period 1 , denoted by $x_{i}$ is

$$
x_{i}=\frac{\theta-P-R w_{i} v_{\varepsilon}}{R v_{\varepsilon}+\lambda} .
$$

Let $X \equiv \sum_{i=1}^{N} w_{i}$. Imposing the market clearing condition that $\sum_{i=1}^{N} x_{i}=0$, we have

$$
P=\theta-\frac{R v_{\varepsilon}}{N} X
$$

Substituting from P into (1), we have 


$$
x_{i}=\frac{R v_{\varepsilon}}{R v_{\varepsilon}+\lambda}\left(\frac{X}{N}-w_{i}\right)
$$

The total expected revenue of the exchanges (or dealers) offering a market in the security is $\Gamma=0.5 \lambda E\left(\sum_{i=1}^{N} x_{i}^{2}\right)$. We know that

$$
x_{i}^{2}=\frac{R^{2} v_{\varepsilon}^{2}}{\left(R v_{\varepsilon}+\lambda\right)^{2}}\left(\frac{X^{2}}{N^{2}}+w_{i}^{2}-2 w_{i} \frac{X}{N}\right)
$$

Let $v_{X} \equiv \operatorname{var}(X)$. Then, the total expected revenue becomes

$$
\Gamma=\frac{0.5 \lambda R^{2} v_{\varepsilon}^{2}}{\left(R v_{\varepsilon}+\lambda\right)^{2}}\left(\frac{v_{X}}{N^{2}}+v_{w}-\frac{2}{N} \operatorname{cov}\left(X, w_{i}\right)\right)
$$

Now, it is easy to see that $v_{X}=N v_{w}+N(N-1) \rho v_{w}$, while $\operatorname{cov}\left(X, w_{i}\right)=v_{w}+(N-1) \rho v_{w}$. Thus

$$
\Gamma=\frac{0.5 \lambda R^{2} v_{\varepsilon}^{2}}{\left(R v_{\varepsilon}+\lambda\right)^{2}}\left(v_{w}(1-\rho)\left(1-\frac{1}{N}\right)\right)
$$

It is worth noting that total expected revenue $\Gamma=0$ when liquidity shocks are perfectly correlated $(\rho=1)$. In this case, there will be no change in relative investor endowments and therefore, investors will not trade. Similarly, in the case where trading costs are prohibitively high $(\lambda \rightarrow \infty)$ trading volume will converge to zero, causing a corresponding drop to zero in total expected revenue.

Since there are $M$ perfectly-competitive market intermediaries in equilibrium and each intermediary incurs a cost of $c$ to set up trading in the security, then the equilibrium $\lambda$ must be such that the zero expected profit condition holds, i.e., $\Gamma=M c$, or that

$$
\frac{0.5 \lambda R^{2} v_{\varepsilon}^{2}}{\left(R v_{\varepsilon}+\lambda\right)^{2}}\left(v_{w}(1-\rho)\left(1-\frac{1}{N}\right)\right)=M c
$$


In order for a real root to exist for $\lambda$ in the above quadratic equation, the discriminant must satisfy the non-negativity condition given by

$$
R v_{\varepsilon} v_{w}(1-\rho)\left(1-\frac{1}{N}\right) \geq 8 M c .
$$

A market will be offered when (8) is fulfilled. Proposition 1 summarizes our key results pertaining to the likelihood that market intermediaries will offer a market.

Proposition 1. A market is more likely to be offered (a) the lower the cost of setting up the market; (b) the lower the number of market intermediaries; (c) the lower the correlation of liquidity shocks; (d) the higher the number of investors; (e) the higher the risk aversion coefficient; (f) the higher the volatility of liquidity shocks; and (g) the higher the riskiness of the security. In the scenario that is the reverse of the above features, the market collapses (fails to exist).

It is worth noting, in particular, that the market collapse threshold is lowered as investor concentration increases, as measured through both the number of investors in the market, "(d)" and through the extent to which their liquidity shocks are correlated, “(c)." For a given level of correlation, trading volume and the amount of revenue generated by market makers decline with the number of investors, making it more likely that revenues will fall short of the level required to recover the cost of opening the market. This finding supports our argument that the market's exposure to common liquidity risk, and therefore its vulnerability to a collapse, is higher when the securities are concentrated in the hands of a small group of homogeneous large investors rather than a large group of diffuse small investors. Additionally, for a given number of investors, trading volume and market maker revenue decline as the correlation of liquidity shocks increases, once again increasing the likelihood of a market closure. 
The result in "(b)," that reducing the number of market intermediaries makes it more likely that a market will exist, parallels the finding in Glosten (1989). However, in Glosten's model the result is driven by a reduction in the ability of market makers to withstand losses to informed traders when competition reduces their profits. In contrast, our finding shows that this prediction holds even in the absence of asymmetric information. In our setting, an increase in the number of intermediaries reduces their collective ability to withstand a common liquidity shock.

Another interesting aspect of the analysis relates to how the equilibrium spread varies with the endowment correlation. It turns out that this relation is nonmonotonic. One can see from (7) that if one transfers the term involving $\rho$ to the right-hand side, what remains on the left-hand side is nonmonotonic in lambda. So if $\rho$ increases, the right-hand side increases, but a higher or lower $\lambda$ may work to increase the left-hand side in order to restore the equality. The intuition is that if the endowment correlation is high the market wishes to charge a higher spread, but this also has an indirect effect of lowering each investor's trade. In equilibrium, the net effect on the spread balances these effects. If the risk aversion coefficient of investors is sufficiently high, however, the first effect dominates and the increase in the endowment spread increases the equilibrium spread. ${ }^{7}$ Our analysis indicates how equilibrium liquidity depends on the degree of commonality in the liquidity shocks across investors, a parameter that is distinct from quantities related to the degree of asymmetric information (as in Glosten, 1989, or Bhattacharya and Spiegel, 1991).

We now show that price drops can occur as investors update their priors about the likelihood of high and low realizations of the endowment correlation. To do this, we calculate the ex ante expected utility of each investor prior to date 1 . We assume that $\theta$ is ex ante normally distributed with mean zero and variance $v_{\theta}$, and independent of all other random variables. We begin by stating

\footnotetext{
${ }^{7}$ It can be seen from using the implicit function theorem on (7) that the effect of $\rho$ on $\lambda$ is positive if and only if $\mathrm{R}_{\varepsilon}>\lambda$.
} 
the following lemma, which is a standard result on multivariate normal random variables (see, for example, Brown and Jennings, 1989).

Lemma 1. Let $Q(\chi)$ be a quadratic function of the random vector $\chi: Q(\chi)=C+B^{\prime} \chi-\chi^{\prime} A \chi$, where $\chi \sim N(\mu, \Sigma)$, and $A$ is a square, symmetric matrix whose dimension corresponds to that of $\chi$. We then have

$$
\begin{aligned}
E[\exp (Q(\chi))]= & \operatorname{Det}[2 A \Sigma+I]^{-1 / 2} \times \\
& \exp \left(C+B^{\prime} \mu+\mu^{\prime} A \mu+(1 / 2)\left(B^{\prime}-2 \mu^{\prime} A^{\prime}\right)\left(2 A+\Sigma^{-1}\right)^{-1}(B-2 A \mu) .\right.
\end{aligned}
$$

As noted previously, in our case, the wealth of investor $i$, denoted by $K_{i}$, is given by $K_{i}=(\theta+\varepsilon)\left(x_{i}+w_{i}\right)-x_{i}\left(P+0.5 \lambda x_{i}\right)$ where $x_{i}$ is given by (1) and $P$ by (2). In turn, $\lambda$ solves (7). Since all random variables have a mean of zero, and there are no terms linear in the random variables, the ex ante expected utility, $-E\left[\exp \left(-R K_{i}\right]\right.$ is given by $-\operatorname{Det}[2 A \Sigma+I]^{-1 / 2}$, where $\Sigma$ is the variance covariance matrix of $\left[X, w_{i}, \varepsilon, \theta\right]$, and $A$ is $-R$ times the quadratic form implied by the expression for $K_{i}$. The matrix corresponding to this quadratic form is

$$
\left[\begin{array}{cccc}
\frac{R^{2} v_{\varepsilon}^{2}}{N^{2}\left(\lambda+R v_{\varepsilon}\right)} & \frac{-(1 / 2) v_{\varepsilon}\left(\lambda+2 R v_{\varepsilon}\right)}{2 N\left(\lambda+R v_{\varepsilon}\right)} & \frac{(1 / 2) R v_{\varepsilon} N}{\left(\lambda+R v_{\varepsilon}\right)} & 0 \\
\frac{-(1 / 2) v_{\varepsilon}\left(\lambda+2 R v_{\varepsilon}\right)}{2 N\left(\lambda+R v_{\varepsilon}\right)} & \frac{\lambda R v_{\varepsilon}}{2\left(\lambda+R v_{\varepsilon}\right)} & \frac{\lambda}{2\left(\lambda+R v_{\varepsilon}\right)} & 1 / 2 \\
\frac{(1 / 2) R v_{\varepsilon} N}{\left(\lambda+R v_{\varepsilon}\right)} & \frac{\lambda}{2\left(\lambda+R v_{\varepsilon}\right)} & 0 & 0 \\
0 & 1 / 2 & 0 & 0
\end{array}\right]
$$

Given that the wealth from not trading is given simply by $(\theta+\varepsilon) w_{i}$, it can easily be shown that the expected utility from not being able to trade is given by the simple expression

$$
-\frac{1}{\operatorname{Det}\left[1-R^{2} v_{w}\left(v_{\varepsilon}+v_{\theta}\right)\right]^{1 / 2}}
$$


We denote the two expected utilities (from being able to trade and not being able to trade) as $E U_{t}$ and $E U_{n t}$, respectively. Consider the following scenario. Suppose that the endowments are realized (and, possibly, the market opens) at time 1. At time -1, the prior distribution of the endowment correlation is $\rho_{l}$ with probability $1-\pi$ and $\rho_{h}>\rho_{l}$ with probability $\pi$. Also, suppose that $\rho_{h}$ is a correlation level that causes the market to shut down (i.e., violates (8)). Then, the certainty equivalent at date -1 (also the shadow price of the security) is given by $(1 / R) \ln \left[(1-\pi) E U_{t}+\pi E U_{n t}\right]$, where $E U_{t}$ is evaluated at $\rho=\rho_{l}$. At date 0 , the true endowment correlation is realized. In general, if it turns out to be the low value, the shadow price will rise, and if it turns out to be the high value, the shadow price will fall. If $\rho_{l}$ is realized, the new certainty equivalent $(\mathrm{CE})$ is simply $-1 / R \operatorname{Det}\left[E U_{t}\right]^{-1 / 2}$, whereas if $\rho_{h}$ is realized, the corresponding $\mathrm{CE}$ is $-1 / R \operatorname{Det}\left[E U_{n t}\right]^{-1 / 2}$.

As a numerical illustration, consider the following parameter values: $M=1, c=0.01, R=$ $0.2, N=100 ; \rho_{h}=0.9, \rho_{l}=0.1 ;$ all other parameters are set to unity. For $\rho=\rho_{h}$, no trade takes place. For $\rho=\rho_{l}$, trade does take place, and, from (7), there are two values of $\lambda$ that are consistent with equilibrium, 0.029 , and 1.35. Picking the higher value, 1.35, implies that the difference in certainty equivalents (i.e., the change in the shadow price of the security) across dates 1 and 0 is +3.10 when $\rho$ is revealed to be the lower value, 0.1 , and -4.06 when it is revealed to be the higher value of 0.9. Thus, the shadow price of the security drops (rises) as market participants discover that the commonality in liquidity shocks is high (low). This illustration demonstrates how sharp price decreases can occur as the beliefs of market participants about the possibility of not being able to trade shift over time. 


\subsection{Learning about liquidity}

The above analysis proceeded on the assumption that market participants had perfect foresight about market liquidity and rationally incorporated their beliefs in asset prices. Furthermore, the decision by market makers to open or close the secondary market was assumed to be exogenous to the model. Next, we focus on the question of how market makers form beliefs about future market liquidity, and how this process can lead to an endogenous shift from a liquid to an illiquid market. Since the decision to open or close a market in our setting rests exclusively with market makers, we assume for simplicity that new generations of traders enter the market in each period while market makers span multiple periods.

Each round of trade is followed by a period where the security pays off a random liquidation amount to investors, and after this payout, a new round of trade with a new generation of outside investors starts afresh. We label each pair of trading and liquidation rounds as belonging to time $\mathrm{n}$. The structure of security payoffs and endowments is the same as in the previous section, and each random variable at time $\mathrm{n}$ is provided a subscript of $\mathrm{n}$. The variables $\theta_{\mathrm{n}}, \varepsilon_{\mathrm{n}}$, and $\mathrm{w}_{\mathrm{in}}$, are mutally independent. Furthermore, these variables have common variances of $\mathrm{v}_{\theta}, \mathrm{v}_{\varepsilon}$, and $\mathrm{v}_{\mathrm{w}}$, respectively, for all $\mathrm{n}$.

In our model, market makers deduce the degree of liquidity of the market by observing realizations of correlations in past periods. As before, assume that the endowment correlation is either $\rho_{l}$ (low commonality state) or $\rho_{h}$ (high commonality state). Each period's realization of the endowment correlation is revealed following the liquidation payoff. We also assume that the decision to offer the market is made prior to the realization of the true endowment correlation.

As we demonstrate, when the true probability of a high commonality state is low, a continued sequence of experiences with low commonality states can cause market makers to underestimate the 
probability of a high commonality state. In our model, market makers update their beliefs in Bayesian fashion, so that their subjective probability of a high commonality state progressively diminishes as the sequence of periods without a high commonality state continues. This can cause security prices to deviate from the level that reflects the true probability of a high commonality state. A reevaluation occurs only when market participants experience a liquidity shock that turns out to have high commonality.

Market makers offer markets based on their subjective (uniform across all market makers) probability estimate of the occurrence of the high commonality state. Under perfect competition, the zero expected profit condition underlying (7) and (8) above must now hold in each individual period that they decide to offer a market. At the outset, we assume that the subjective probability estimate of the high commonality state is low enough for market makers to open the market. The indicator $\chi_{t}$ $=1$ if the high commonality state occurs and 0 otherwise.

Market makers form a subjective probability estimate of the occurrence of the high commonality state by observing a sequence of prior market states. As before denote the probability of the high commonality state as $\pi$, which corresponds to the proportion of states in the sequence that turns out to have high commonality. The prior probability density function of $\pi$ is assumed to be a beta distribution with parameters $\alpha>0$ and $\beta>0:^{8}$

$$
f(\pi \mid \alpha, \beta)=\frac{\Gamma(\alpha+\beta)}{\Gamma(\alpha) \Gamma(\beta)} \pi^{\alpha-1}(1-\pi)^{\beta-1}, \quad 0 \leq \pi \leq 1
$$

whose unconditional mean is $\mathrm{E}(\pi)=\alpha /(\alpha+\beta)$, where $\alpha$ and $\beta$ are chosen appropriately based on the available prior information about $\pi$. Lemma 2 provides the result for the corresponding posterior probability distribution (see, for example, DeGroot (1970)).

\footnotetext{
${ }^{8}$ The beta distribution is widely used to represent distributions of variables that naturally lie between 0 and 1 , such as proportions and probability estimates. See DeGroot (1970) and Guttentag and Herring (1984).
} 
Lemma 2. The posterior probability distribution after observing a sequence of $n+1$ states is also a beta distribution with parameters $\alpha^{\prime}=\alpha+y$; and $\beta^{\prime}=\beta+n-y$ :

$$
g\left(\pi \mid \chi_{t-n-1}, \ldots, \chi_{t-1}\right)=\frac{\Gamma\left(\alpha^{\prime}+\beta^{\prime}\right)}{\Gamma\left(\alpha^{\prime}\right) \Gamma\left(\beta^{\prime}\right)} \pi^{\alpha^{\prime}-1}(1-\pi)^{\beta^{\prime}-1}
$$

where $y$ is the total number of high commonality states observed in this sequence.

We will assume that a new sequence of observations begins if the immediately preceding event is a high commonality state. Proposition 2 specifies how market participants form their subjective probability beliefs about future market liquidity by observing past liquidity.

Proposition 2. Market makers form their subjective probability beliefs as follows:

1. If the preceding $n+1$ events are low commonality states, the subjective probability assessment after observing $n+1$ low commonality states will be:

$$
E\left[\pi \mid \sum_{\tau=t-n-1}^{t-1} \chi_{t}=0\right]=\frac{\alpha}{\alpha+\beta+n} .
$$

As $n$ increases, the subjective probability of a high commonality state goes to zero.

2. If the immediately preceding event is a high commonality state, the subjective probability assessment will be:

$$
E\left(\pi \mid \chi_{t-1}=1\right)=\frac{\alpha+1}{\alpha+\beta} .
$$

Note that:

$$
\frac{\alpha}{\alpha+\beta+n}<\frac{\alpha}{\alpha+\beta}<\frac{\alpha+1}{\alpha+\beta}
$$

The occurrence of a high commonality state (HCS) will cause market participants to overestimate initially the probability that such a state will reoccur. But, if the market reopens, as the number of periods without an additional HCS increases, the subjective probability of a HCS will decline, ultimately falling below the unconditional probability. This shift in subjective probability of a high 
commonality state is the critical determinant of whether market makers will open the secondary market. For convenience, in the ensuing discussion, we will denote as $\mathrm{E}_{\mathrm{c}}(\pi)$ the conditional expectation of $\pi$ after any sequence of observations of low or high commonality states.

It is straightforward to modify (8) to define a threshold level, $\xi$, of the subjective expected probability of a high commonality state above which dealers will not be willing to make a secondary market. Indeed, by the law of iterated expectations, observing that $\mathrm{E}(\rho)=\xi \rho_{\mathrm{h}}+[1-\xi] \rho_{1}$ at the threshold expectation of $\pi$, and substituting for the expected value of $\rho$ in place of $\rho$ in (8), we find that $\xi=\left(\rho_{\mathrm{h}}-\rho_{\mathrm{l}}\right)^{-1}\left[1-\rho_{\mathrm{l}}-8 \mathrm{McN} /\left\{(\mathrm{N}-1) \mathrm{Rv}_{\varepsilon} \mathrm{V}_{\mathrm{w}}\right\}\right]$.

Whether the secondary market is reopened after a HCS depends on the unconditional expected probability $\mathrm{E}(\pi)=\alpha /(\alpha+\beta)$ of this state . Note that after the first occurrence of a HCS, the conditional expected probability of a $\mathrm{HCS}, \mathrm{E}_{\mathrm{c}}(\pi)$, rises above $\mathrm{E}(\pi)$. If $\mathrm{E}(\pi)$ is sufficiently high, $\mathrm{E}_{\mathrm{c}}(\pi)$ may rise above the threshold level $\xi$. As a result, market makers will not reopen the secondary market. In contrast, when $\mathrm{E}(\pi)$ is low, even though $\mathrm{E}_{\mathrm{c}}(\pi)$ may rise above $\mathrm{E}(\pi)$, it may not rise above $\xi$ and therefore, market makers may reopen the secondary market. Our theoretical framework thus shows how investor confidence in the liquidity of a market can collapse in the event of a high commonality state, leading to either transitory or permanent illiquidity in the secondary market depending on how the expectations of market participants are changed by the occurrence of the HCS.

Our model describes how common liquidity risk can cause a market collapse despite lack of any information asymmetry across market participants or a significant deviation of asset prices from their fundamental value. This happens, for example, when ownership by a relatively narrow group of large investors leads to a high degree of commonality in liquidity shocks. While we argue that the model is consistent with the perp collapse and has relevance for other markets where narrow 
ownership or other factors increase systemic liquidity risk, it is nonetheless useful to consider whether other explanations are applicable as well. We turn to this question in the next section, drawing from the available evidence on the performance of the perp market especially following the collapse.

\section{Alternative Explanations and a Postscript on the Perp Market}

In this section we consider some plausible alternative hypotheses for the collapse of the perp market and discuss the lack of recovery in market liquidity. We begin by considering the possibility that the collapse of the market for perps was driven by a credit shock rather than a liquidity shock. For example, did the rumored tightening of capital adequacy requirements cause investors to fear that more banks would have trouble meeting minimum capital standards and thus default on their perps? We have found no evidence of any price movements in other outstanding securities by perp issuers that would be consistent with such a hypothesis. Overall, the high credit quality of perps makes the credit decline hypothesis less plausible and we have not detected any change in credit quality either immediately preceding or following the market collapse.

The refutation of the rumor notwithstanding, it is possible that the market may have factored in a higher probability of future adverse regulation. However, there has been no such development in the 20 years following the collapse. Ultimately, even if there was a reason for investors to factor in a lower credit quality, this should not have precluded them from trading. This is not what has happened. Although 47 perps remain outstanding, the loss of liquidity appears to be permanent.

Another possibility is that perps may have been overpriced relative to their fundamental value prior to the collapse, especially since from a theoretical standpoint it is possible that perps were more susceptible to mispricing than securities that have a finite maturity. Since all the perps were issued at par in the primary market and continued to trade at par in the secondary market, such mispricing, if any, had to have persisted from the outset. 
Perps were priced in the primary market relative to dated FRNs, initially at annual spreads of 20-25 basis points, but since both securities had the same duration ( 3 to 6 months depending on the coupon reset interval) and the same initial liquidity, the price differential presumably compensated investors for the higher holding period credit risk of perps. After the collapse, the annual yield differential increased by approximately an order of magnitude to around 200-250 basis points. A spread of this magnitude seems unrealistic for dated and perpetual securities of comparable credit quality. This seems to be confirmed by the fact that primary issuance of perps came to a halt following the collapse. Moreover, even if this higher spread was deemed reasonable by investors, we would have expected to see the market remain liquid at the lower prices. As noted previously, this did not happen. It seems more plausible that the higher yield spread following the collapse was compensation for the lack of liquidity in the market, as predicted by our model.

It is also possible that there was information asymmetry pertaining to perp fundamentals across different market participants, giving rise to the collapse. However, in the case of perps, there has been no significant information arriving in the market in the 20 years following the collapse (either pertaining directly to perp cash flows, or indirectly about regulation of the perp market) which would suggest that some perp market participants had information that others did not have prior to the collapse. Additionally, the theories of market collapse based on information asymmetry would predict a revival of liquidity when all the information privately held by investors is eventually reflected in prices. This has not happened in the perp market.

Finally, it is possible that the perp collapse was triggered by the removal of a clientele effect (making perps more attractive to bank investors) or an implicit regulatory subsidy (resulting from banks being permitted to hold reciprocal capital obligations). While banks were the dominant investors in this market, however, any potential regulatory subsidies (for example, the benefit of increasing regulatory capital by issuing perps) accrue only to bank issuers, not bank investors. We 
have not found any evidence of a benefit from holding perps that accrues exclusively to bank investors. Moreover, Japanese banks, which accounted for most of the holdings of perps, did not issue perps in this era and so they were not beneficiaries of an implicit regulatory subsidy.

Although most of the perps issued during the 1984-86 period remain outstanding, the market has not recovered its liquidity. Several attempts have been made to restore liquidity to perps (and arbitrage the price spread between perps and dated FRNs) by repackaging the promised cash flows as instruments with fixed maturities (Meerschwam, 1987). The basic idea was to add a high quality zero-coupon bond (an instrument that was all principal repayment with no interest payments) to the perp (an instrument with only interest payments and no principal repayment) to create a synthetic, dated FRN that would appeal to a broader range of investors. These efforts have met with limited success, ironically for the same reason that keeps the market illiquid in the first place: the unwillingness of Japanese banks to recognize a loss by exchanging their perps at below par value due to Japanese regulatory authorities permitting them to defer recognition of capital losses until the perps were sold. Market makers and other potential market participants believed that any rise in the prices of perps would be swiftly met by sales of perps by Japanese banks and so they were unwilling to buy. But, so long as perps traded below par, Japanese banks, which were under international pressure to increase regulatory capital, were not eager to sell below par and realize a capital loss, particularly since the stream of cash flows from perps was never in doubt.

The collapse of the secondary market for perps caused a sharp decline in prices of $12 \%$ to $25 \%$ due to the collapse of the marketability premium. Although indicative prices continue to be reported for most outstanding issues of perps, they reflect sporadic transactions that are negotiated between the buyer and seller and not prices at which dealers are prepared to trade. As such, they are consistent with the discount applied to assets in other illiquid markets (see, for example, Silber, 1991). 


\section{Concluding Remarks}

The perp episode emphasizes the importance of a broad investor base in establishing and maintaining liquid secondary markets. While the perp market initially became very liquid despite its narrow investor base consisting principally of Japanese banks, its liquidity permanently vanished once a common liquidity shock caused market intermediaries to negatively reassess the risk of keeping the market open.

Our study provides new insights into why markets collapse. As we have shown, markets can collapse even in the absence of the two conditions that are thought in the literature to give rise to a collapse: the bursting of a bubble concerning fundamental value or information asymmetry about the value of the fundamental determinants of asset prices. Our theoretical framework and the perp episode demonstrate that market collapse can be an endogenous phenomenon, independent of the

fundamental value of assets, but critically dependent on the commonality in the liquidity needs of the investor clientele that holds the assets.

Our analysis has important implications that apply to the ownership-liquidity tradeoff. Specifically, we suggest that to avoid market failures of the type that occurred in the perp market, security offerings need to be marketed to a broad diverse investor base, which would not only lower the cost of capital by increasing liquidity, but also prevent market collapse and closure of a future source of financing. This benefit of broad-based ownership has not been previously emphasized in the literature, and counters the traditional reason for concentrated ownership: that the latter leads to more effective corporate governance.

While the perp episode provides an ideal experimental setting to analyze the effect of liquidity shocks without the complications of asymmetric information, it may also seem like an isolated incident. We would argue otherwise. Ju, Linn and Zhu (2007) document that the U.S. natural gas market suffered diminished liquidity for about a month when its largest intermediary 
Enron collapsed. This episode is comparable to the perp collapse in the sense that the fundamentals of the natural gas market were not in question at any time. Volcker (1986) documents an episode where the U.S. Treasury market underwent a near-collapse in November 1985 when a software glitch created a liquidity problem at a major intermediary in government securities, the Bank of New York. A serious crisis was averted only by the Federal Reserve providing an overdraft of $\$ 30$ billion to BNY, which was more than 30 times BNY's primary capital.

One potential limitation of our model is that it does not allow for the possibility of shocks to fundamentals or for asymmetric information across market participants with regard to fundamentals. While as in the perp case the trigger for a collapse need not arise from asset fundamentals, a view that is supported by the growing empirical evidence of commonality in liquidity, incorporating these elements will provide a richer set of empirical implications and help to strengthen our understanding of the interactions between shocks to asset fundamentals and shocks to investor and market liquidity. 


\section{References}

Allen, F., Gale, D., 2000, Bubbles and crises, Economic Journal 110, 236-255.

Bhattacharya, U., Spiegel, M., 1991, Insiders, outsiders and market breakdowns, Review of Financial Studies 4, 255-282.

Bhide, A., 1993, The hidden costs of stock market liquidity, Journal of Financial Economics 34, 31-51.

Bolton, P., von Thadden, E.-L., 1998, Blocks, liquidity, and corporate control, Journal of Finance 53, 1-25.

Brennan, M.J., Subrahmanyam, A., 1996, Market microstructure and asset pricing: On the compensation for illiquidity in stock returns, Journal of Financial Economics 41, 441-464.

Brown, D.P., Jennings, R.H., 1989, On technical analysis, Review of Financial Studies 2, $527-$ 551.

Brunnermeier, M.K., Pedersen, L.H., 2007, Market liquidity and funding liquidity, Unpublished working paper.

Chordia, T., Roll, R., Subrahmanyam, A., 2000, Commonality in liquidity, Journal of Financial Economics 56, 3-28.

Comptroller of the Currency, Federal Deposit Insurance Corporation and Federal Reserve Board, 1987, Joint News Release, January 8 (U.S. Government Printing Office, Washington, DC).

DeGroot, M.H., 1970, Optimal Statistical Decisions, McGraw Hill, New York.

Edelen, R.M., 1999, Investor flows and the assessed performance of open-end mutual funds, Journal of Financial Economics 53, 439-466.

Fernando, C.S., 2003, Commonality in liquidity: transmission of liquidity shocks across investors and securities, Journal of Financial Intermediation 12, 233-254.

Financial Times, 1986, “FRN traders struggle to restore stability,” December 4, p. 38.

Glosten, L.R., 1989, Insider trading, liquidity and the role of the monopolist specialist, Journal of Business 62, 211-235.

Glosten, L.R., Milgrom, P.R., 1985, Bid, ask and transaction prices in a specialist market with heterogeneously informed traders, Journal of Financial Economics 13, 71-100.

Gromb, D., Vayanos, D., 2002, Equilibrium and welfare in markets with financially constrained arbitrageurs, Journal of Financial Economics 66, 361-407.

Guttentag, J.M., Herring, R.J., 1984, Credit rationing and financial disorder, Journal of Finance 39, 1359-1382.

Hasbrouck, J., Seppi, D., 2001. Common factors in prices, order flows and liquidity, Journal of Financial Economics 59, 383-411. 
International Financing Review (IFR), various issues, including July 1987 Special Issue on Perpetual Floating Rate Notes.

Ju, J.D., Linn, S.C., Zhu, Z., 2007, Price dispersion in a model with middlemen and oligopolistic market makers, Unpublished working paper.

Kahn, C., Winton, A., 1998, Ownership structure, speculation, and shareholder intervention, Journal of Finance 53, 99-129.

Kindleberger, C.P., 1978, Manias, Panics and Crashes: A History of Financial Crises Basic Books, New York.

Kyle, A.S., Xiong, W., 2001, Contagion as a wealth effect, Journal of Finance 56, 1401-1440.

Maug, E., 1998, Large shareholders as monitors: Is there a trade-off between liquidity and control? Journal of Finance 53, 65-98.

Meerschwam, D.M., 1987, Schroders' perpetual floating rate note exchange offer, Case 9-288057, Harvard Business School.

Miller, M.H., 1991, Financial Innovations and Market Volatility, Blackwell Publishers, Cambridge, MA.

Pástor, L., Stambaugh, R.F., 2003, Liquidity risk and expected stock returns, Journal of Political Economy 111, 642-685.

Pritsker, M., 2004, Large investors: implications for equilibrium asset returns, shock absorption, and liquidity, Unpublished working paper.

Sias, R.W., 2004, Institutional herding, Review of Financial Studies 17, 165-206.

Silber, W.L., 1991, Discounts on restricted stock: The impact of illiquidity on stock prices, Financial Analysts Journal 47, 60-64.

Spiegel, M., Subrahmanyam, A., 1992, Informed Speculation and Hedging in a Noncompetitive Securities Market, Review of Financial Studies 5, 307-329.

Volcker, P.A., "Statement before the Subcommittee on Domestic Monetary Policy of the Committee on Banking, Finance and Urban Affairs, U.S. House of Representatives, December 12, 1985," Federal Reserve Bulletin, February 1986, 115-127.

Wagster, J.D., 1996, Impact of the 1988 Basle Accord on international banks, Journal of Finance 51, 1321-1346.

Williams, R., Hole, M., 1987, Refloating the floating rate note (FRN) market: the view from CSFB, Journal of International Securities Markets, Autumn, 5-16. 


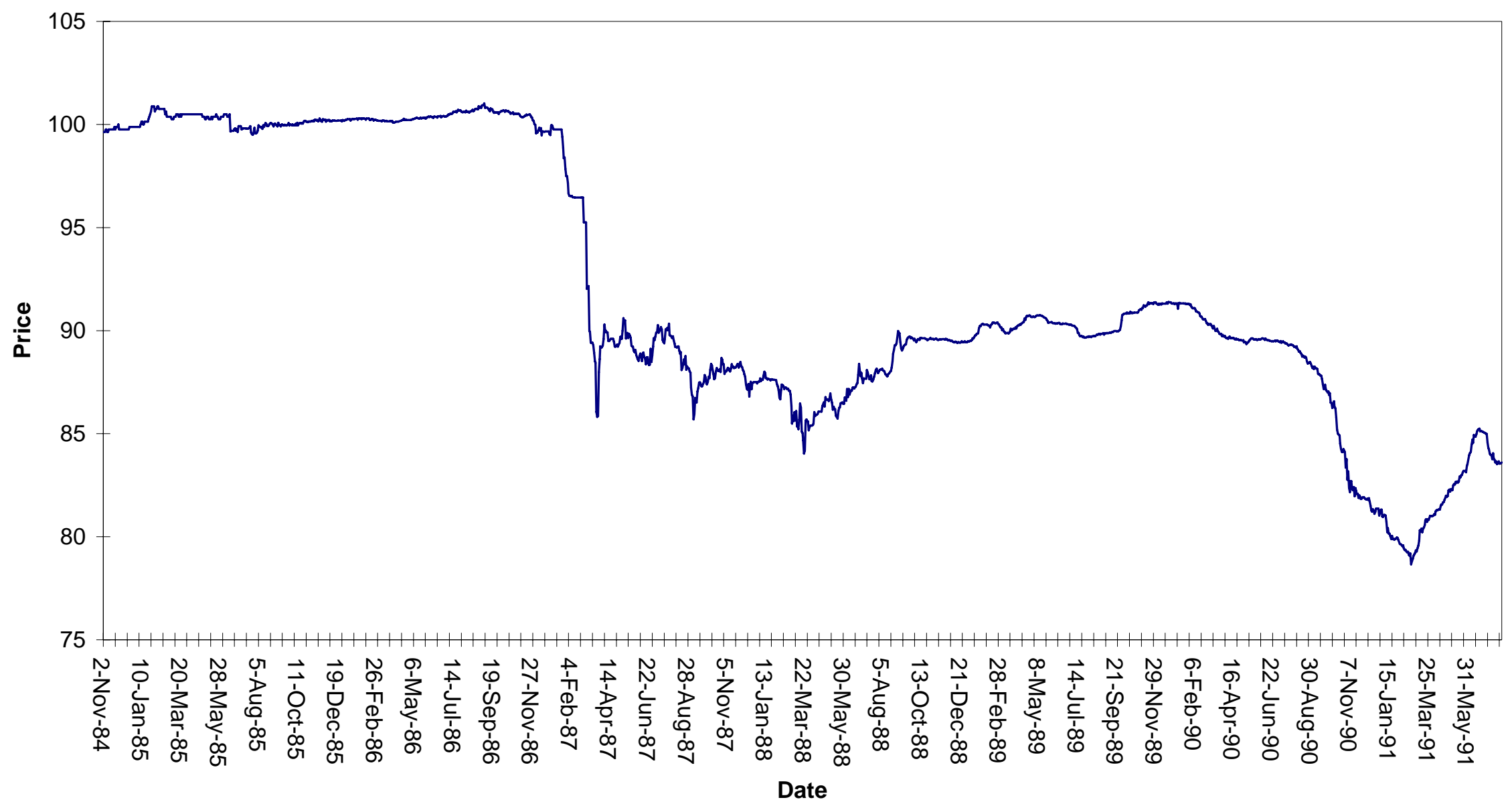

Figure 1: Behavior of perp price index. This figure plots the value from November 1984 through June 1991 of a price index of eleven perps issued by British Clearing Banks. The sudden collapse and lack of recovery of the secondary market is clearly evident. However, prices after the collapse are updated infrequently based on the last reported transaction, and may not be current. Data source: Datastream. 